\title{
Editorial: The Role of Microbial Communities in Tropical Ecosystems
}

\author{
Silvia Pajares ${ }^{1 *}$, Brendan J. M. Bohannan ${ }^{2}$ and Valeria Souza ${ }^{3}$ \\ 1 Unidad Académica de Ecología y Biodiversidad Acuática, Instituto de Ciencias del Mar y Limnología, Universidad Nacional \\ Autónoma de México, Mexico City, Mexico, ${ }^{2}$ Department of Biology, Institute of Ecology and Evolution, University of Oregon, \\ Eugene, OR, USA, ${ }^{3}$ Departamento de Ecología Evolutiva, Instituto de Ecología, Universidad Nacional Autónoma de México, \\ Mexico City, Mexico
}

Keywords: microbial ecology, tropical ecosystem, environmental factors, land use change, microbial processes and diversity

\section{The Editorial on the Research Topic}

\section{The Role of Microbial Communities in Tropical Ecosystems}

Microorganisms represent the largest proportion of the Earth's biodiversity and play an essential role in ecosystem processes, providing functions that ultimately sustain all of life (Falkowski et al., 2008; Prosser, 2012). Understanding the link between ecosystem functioning and the distribution of microbial diversity is essential to predict ecosystem responses to a changing environment (de Vries and Shade, 2013; Logue et al., 2015). With the rapid development of molecular-based techniques, a new interest in understanding the distribution patterns and functional traits of microbial communities has emerged (Fuhrman, 2009; Strickland et al., 2009; Bradford and Fierer, 2012; Krause et al., 2014). However, most of this research has been focused in temperate regions, and the principal mechanisms controlling microbial community variation within the tropics are poorly known.

Tropical ecosystems are different in important ways from those of temperate regions. They are a major reservoir of plant and animal biodiversity and play important roles in global climate regulation and biogeochemical cycling (Gibson et al., 2011; Townsend et al., 2011). They are also under great threat due to the conversion of tropical ecosystems to other uses (Bawa et al., 2004; Stork et al., 2009). Thus, in the context of global change, it is crucial to understand how environmental factors, biogeographic patterns, and land use changes interact to influence the structure and function of microbial communities in these ecosystems.

It is possible that different rules apply to microbial life in tropical ecosystems. For instance, elevated nitrogen deposition by anthropogenic activities may exacerbate phosphorus deficiency in tropical regions, in ways uncommon in temperate ecosystems (Vitousek et al., 2010). However, it is poorly understood how phosphorus availability affects soil microbes (Heuck et al., 2015), or how microbial processes interact with nitrogen deposition in tropical ecosystems (Hietz et al., 2011). Moreover, the distribution of microbes not only is related to environmental factors, but also can vary in relation to temporal and spatial scale (Martiny et al., 2006; Shade et al., 2012). These factors influence biodiversity patterns of larger organisms, but their role in microbial diversity remains unclear (Barberán et al., 2014), especially in tropical systems. In addition, little is known about microbial community responses to disturbance in the tropics. Land use is one of the main drivers of biodiversity alteration in plant and animal communities, especially in tropical areas, where natural ecosystems such as forests are being rapidly altered by conversion to agriculture and other uses (Barnes et al., 2014). Understanding the effects of land use change on soil microorganisms is also a major conservation frontier.

The primary aim of this Research Topic is to explore the environmental and anthropological factors controlling the composition and functional diversity of microbial communities in tropical 
systems. For example, Fanin et al. reported that temporal differences in nitrogen and phosphorus availability in tropical forest soils are critical for the activity and the structure of microbial decomposer communities. Tripathi et al. observed that within tropical rainforests there is a strong degree of ecological differentiation in soil and, as a consequence soil properties together with bacterial and fungal communities varied significantly between forest types. Lee et al. documented the distribution of methanotrophs and methanogens along a depth gradient in a tropical rice paddy, and looked for patterns with oxygen, methane, and organic carbon concentrations in these soils. The influence of environmental and anthropogenic factors, such as nitrogen deposition and land-use change, on the key players in the nitrogen cycle was also assessed in a general review Pajares and Bohannan. This review highlights the large gaps in our understanding of microbially mediated nitrogen processes in tropical forest soils and identifies important areas for future research.

Due to ongoing and widespread deforestation of tropical ecosystems for pasture and crop cultivation, there is an urgent need to evaluate their soil biological diversity. This Research Topic presents new findings on the impact of rainforest conversion on soil microbial community structure, diversity and ultimately functional traits Schneider et al. Particularly in the wet season, land use change from rainforest to agriculture reduced the abundance of different functional microbial groups related to the soil carbon and nitrogen cycles Lammel et al. There is limited knowledge regarding the diversity of important groups of microorganisms in the tropics. Thus, other contributions studied how abundant lineages in soils, such as Acidobacteria Navarrete et al., and Verrucomicrobia Ranjan et al., responded to forest-topasture conversion. These studies demonstrate that such groups can be useful as indicators of agricultural impact on tropical ecosystems. Furthermore, the isolation and characterization of two novel moderately thermophilic and acid-tolerant obligate methanotrophs recovered from a tropical methane seep topsoil habitat were described Islam et al.

\section{REFERENCES}

Barberán, A., Casamayor, E. O., and Fierer, N. (2014). The microbial contribution to macroecology. Front. Microbiol. 5:203. doi: 10.3389/fmicb.2014.00203

Barnes, A. D., Jochum, M., Mumme, S., Haneda, N. F., Farajallah, A., Widarto, T. H., et al. (2014). Consequences of tropical land use for multitrophic biodiversity and ecosystem functioning. Nat. Commun. 5:5351. doi: 10.1038/ncomms6351

Bawa, K. S., Kress, W. J., Nadkarni, N. M., Lele, S., Raven, P. H., Janzen, D. H., et al. (2004). Tropical ecosystems into the 21 st century. Science 306, 227-228. doi: $10.1126 /$ science. $306.5694 .227 \mathrm{~b}$

Bradford, M., and Fierer, N. (2012). "The biogeography of microbial communities and ecosystem processes: implications for soil and ecosystem models," in Soil Ecology and Ecosystem Services, eds D. H. Wall, R. D. Bardgett, V. BehanPelletier, J. E. Herrick, H. Jones, K. Ritz, J. Six, D. R. Strong, and W. H. van der Putten (Oxford: Oxford University Press), 189-200.

de Vries, F. T., and Shade, A. (2013). Controls on soil microbial community stability under climate change. Front. Microbiol. 4:265. doi: 10.3389/ fmicb.2013.00265

Falkowski, P. G., Fenchel, T., and Delong, E. F. (2008). The microbial engines that drive Earth's biogeochemical cycles. Science 320, 1034-1039. doi: 10.1126/science. 1153213
Some contributions to this Research Topic have focused on how land management practices impact microbially-mediated processes in tropical soils through the alteration of microbial communities. Reverchon et al. showed the influence of different tree plantation systems on nitrogen retention and the abundance of nitrogen functional genes, while Wood et al. concluded that the direct effect of farm management (rather than the indirect effect through changes in the taxonomic and functional diversity of microbial communities) was the dominant control of nutrient loss from smallholder tropical agriculture. Both studies emphasize the necessity of further research on incorporating microbial dynamics into plantation management to improve productivity while mitigating soil fertility loss. Xiong et al. observed that sustainable agricultural management regimes, such as crop rotation, of commercially important crops in tropical regions significantly increased soil fungal diversity and might be a meaningful strategy to prevent vanilla Fusarium wilt disease.

Finally, one of the biggest threats facing frog populations in montane tropical systems is a lethal skin disease caused by a chytrid fungus. The composition of the frog skin microbiota can strongly influence many facets of frog health and disease resistance. Field survey data published as part of our Research Topic has demonstrated that the frog skin microbiota is producing broadly similar sets of anti-fungal metabolites across different host species and sites Belden et al.

In summary, the contributions to this Research Topic showcase the current knowledge regarding microbial ecology in tropical ecosystems, identify many challenges and questions that remain to be addressed and open up new horizons in our understanding of the environmental and anthropological factors controlling microbial communities in these important ecosystems.

\section{AUTHOR CONTRIBUTIONS}

SP produced the first draft of the editorial, and all authors edited the editorial.

Fuhrman, J. A. (2009). Microbial community structure and its functional implications. Nature 459, 193-199. doi: 10.1038/nature 08058

Gibson, L., Lee, T. M., Koh, L. P., Brook, B. W., Gardner, T. A., Barlow, J., et al. (2011). Primary forests are irreplaceable for sustaining tropical biodiversity. Nature 478, 378-381. doi: 10.1038/nature10425

Heuck, C., Weig, A., and Spohn, M. (2015). Soil microbial biomass C:N:P stoichiometry and microbial use of organic phosphorus. Soil Biol. Biochem. 85, 119-129. doi: 10.1016/j.soilbio.2015.02.029

Hietz, P., Turner, B. L., Wanek, W., Richter, A., Nock, C. A., and Wright, S. J. (2011). Long-term change in the nitrogen cycle of tropical forests. Science 334, 664-666. doi: 10.1126/science.1211979

Krause, S., Le Roux, X., Niklaus, P. A., van Bodegom, P. M., Lennon, T., J. T., Bertilsson, S., et al. (2014). Trait-based approaches for understanding microbial biodiversity and ecosystem functioning. Front. Microbiol. 5:251. doi: 10.3389/fmicb.2014.00251

Logue, J. B., Findlay, S. E. G., and Comte, J. (2015). Editorial: microbial responses to environmental changes. Front. Microbiol. 6:1364. doi: 10.3389/ fmicb.2015.01364

Martiny, J. B. H., Bohannan, B. J. M., Brown, J. H., Colwell, R. K., Fuhrman, J. A., Green, J. L., et al. (2006). Microbial biogeography: putting microorganisms 
on the map. Nat. Rev. Microbiol. 4, 102-112. doi: 10.1038/nrmic ro1341

Prosser, J. I. (2012). Ecosystem processes and interactions in a morass of diversity. FEMS Microbiol. Ecol. 81, 507-519. doi: 10.1111/j.1574-6941.2012.01435.x

Shade, A., Peter, H., Allison, S. D., Baho, D. L., Berga, M., Bürgmann, H., et al. (2012). Fundamentals of microbial community resistance and resilience. Front. Microbiol. 3:417. doi: 10.3389/fmicb.2012.00417

Stork, N. E., Coddington, J. A., Colwell, R. K., Chazdon, R. L., Dick, C. W., Peres, C. A., et al. (2009). Vulnerability and resilience of tropical forest species to land-use change. Conserv. Biol. 23, 1438-1447. doi: 10.1111/j.15231739.2009.01335.x

Strickland, M. S., Lauber, C., Fierer, N., and Bradford, M. A. (2009). Testing the functional significance of microbial community composition. Ecology 90, 441-451. doi: 10.1890/08-0296.1

Townsend, A. R., Cleveland, C. C., Houlton, B. Z., Alden, C. B., and White, J. W. C. (2011). Multi-element regulation of the tropical forest carbon cycle. Front. Ecol. Environ. 9, 9-17. doi: 10.1890/1 00047

Vitousek, P. M., Porder, S., Houlton, B. Z., and Chadwick, O. A. (2010). Terrestrial phosphorus limitation: mechanisms, implications, and nitrogen-phosphorus interactions. Ecol. Appl. 20, 5-15. doi: 10.1890/08-0127.1

Conflict of Interest Statement: The authors declare that the research was conducted in the absence of any commercial or financial relationships that could be construed as a potential conflict of interest.

Copyright (c) 2016 Pajares, Bohannan and Souza. This is an open-access article distributed under the terms of the Creative Commons Attribution License (CC BY). The use, distribution or reproduction in other forums is permitted, provided the original author(s) or licensor are credited and that the original publication in this journal is cited, in accordance with accepted academic practice. No use, distribution or reproduction is permitted which does not comply with these terms. 